\title{
Post-viral Anosmia (Loss of Sensation of Smell) Did Not Begin with COVID-19!
}

\author{
Peter V. Dicpinigaitis ${ }^{1,2}$
}

Accepted: 12 April 2021 / Published online: 24 April 2021

(c) The Author(s), under exclusive licence to Springer Science+Business Media, LLC, part of Springer Nature 2021

In the early stages of the COVID-19 pandemic, anecdotal reports of complete loss or diminution of the sensation of smell accompanying acute infection with SARS-CoV-2, or its aftermath, accumulated rapidly. To many physicians, such an acute symptom was unfamiliar. However, the occurrence of viral respiratory tract infection-induced alteration of smell is a well-established entity, familiar mostly to otorhinolaryngologists, and has been termed post-viral olfactory dysfunction (PVOD) [1-3]. The presumed mechanism is viral-induced damage to the olfactory epithelium. Viruses most commonly implicated in PVOD include rhinovirus, coronavirus, parainfluenza virus, and Epstein-Barr virus [4, 5].

The natural history of PVOD is quite variable. Olfactory dysfunction is often transient and dissipates with the acute viral respiratory illness, but in some the resolution may be protracted. Most but not all patients eventually regain their sense of smell though the process can be prolonged, taking up to 2 years $[2,3,6]$.

Predictable and effective therapeutic protocols have not been established since adequate, prospective clinical trials of potential treatments have not been performed, nor is there a uniform consensus regarding the management of PVOD. A recent consensus statement published by the international Clinical Olfactory Working Group made an overwhelming recommendation for olfactory training and offered more heterogeneous support for a trial of oral corticosteroids [7]. Previous evidence-based reviews [8] and clinical practice guidelines [9] have similarly voiced strong support for olfactory training, with trials of systemic and topical corticosteroids recommended as an option. Indeed, the therapeutic

Peter V. Dicpinigaitis

pdicpin@gmail.com

1 Albert Einstein College of Medicine and Montefiore Medical Center, Bronx, NY, USA

2 Montefiore Medical Center/Einstein Division, 1825 Eastchester Road, Bronx, NY 10461, USA entity with the most robust support is olfactory training [10, 11] as pharmacological therapies have not been properly investigated in clinical trials [12].

Olfactory training involves patients with olfactory dysfunction inhaling a series of four odorants twice daily, for approximately $10 \mathrm{~s}$ each, over a 12 -week period [13]. The four chemicals (odors) employed are phenyl ethyl alcohol [PEA] (rose), eucalyptol (eucalyptus), citronellal (lemon), and eugenol (cloves) [13]. Although proven successful, the mechanism(s) by which olfactory training improves the sensation of smell remain incompletely understood. Functional brain MRI (fMRI) studies of anosmic subjects with PVOD undergoing olfactory training over a 12-week period demonstrated that improvement in olfactory sensation was associated with modifications of functional connections within the olfactory, somatosensory, and integrative networks, which are involved in the processing of chemosensory input [14]. A recent study has shed further light on the apparently unique and dynamic neuroplasticity of the olfactory system [15]. Evaluation of resting-state fMRI imaging before and after 12 weeks of olfactory training revealed that PVOD subjects had increased connectivity within the visual cortex compared with control subjects, which decreased after olfactory training. In addition, four other network connectivity changes were noted after completion of olfactory training [15].

Prompt and significant attention has been granted to PVOD since the onset of COVID-19 and its associated olfactory symptoms [16]. The pathophysiological mechanisms of SARS-CoV-2-associated olfactory dysfunction appear to be identical to those of PVOD [17]. Some guidance regarding the treatment of PVOD due to SARS-CoV-2 has already appeared. A small prospective study demonstrated benefit from a short course of oral corticosteroids in addition to olfactory training, but not from olfactory training alone [18]. The British Rhinological Society expert panel has published consensus guidelines on the management of new onset loss of smell with COVID-19 [19]. In this document, olfactory 
training was recommended for all patients with persistent loss of smell of more than 2 weeks' duration, and oral steroids, steroid rinses, and omega 3 supplements were recommended to be considered on an individual basis [19].

Although PVOD was a well-established entity prior to COVID-19, guidance on optimal treatment strategies was lacking due to an absence of properly performed clinical trials. As the mechanisms of PVOD and COVID-19-associated olfactory dysfunction are likely to be similar or identical [17], perhaps the current pandemic will facilitate the first-ever randomized, controlled trials that will, hopefully, inform management of both SARS-CoV-2-related and unrelated PVOD. Furthermore, an opportunity arises for physicians outside of the field of otorhinolaryngology to familiarize themselves with PVOD and with the concept of olfactory training which, as noted above, is considered first-line management for this disorder.

\section{Declarations}

Conflict of interest Peter V. Dicpinigaitis, MD, is the Editor-in-Chief of $L U N G$.

\section{References}

1. Moran DT, Jafek BW, Eller PM et al (1992) Ultrastructural histopathology of human olfactory dysfunction. Microsc Res Tech 23:103-110

2. Seiden AM (2004) Postviral olfactory loss. Otolaryngol Clin N Am 37:1159-1166

3. Welge-Lussen A, Wolfensberger M (2006) Olfactory disorders following upper respiratory tract infections. Adv Otorhinolaryngol 63:125-132

4. Suzuki M, Saito K, Min WP et al (2007) Identification of viruses in patients with postviral olfactory dysfunction. Laryngoscope 117:272-277

5. Wang JH, Kwon HJ, Jang YJ (2007) Detection of parainfluenza virus 3 in turbinate epithelial cells of postviral olfactory dysfunction patients. Laryngoscope 117:1445-1449

6. Lee DY, Lee WH, Wee JH et al (2014) Prognosis of postviral olfactory loss: follow-up study for longer than one year. Am J Rhinol Allergy 28:419-422
7. Addison AB, Wong B, Ahmed T et al (2021) Clinical Olfactory Working Group consensus statement on the treatment of postinfectious olfactory dysfunction. J Allergy Clin Immunol. https:// doi.org/10.1016/j.jaci.2020.12.641

8. Hura N, Xie DX, Choby GW et al (2020) Treatment of post-viral olfactory dysfunction: an evidence-based review with recommendations. Int Forum Allergy Rhinol 10:1065-1086

9. Miwa T, Ikeda K, Ishibashi T et al (2019) Clinical practice guidelines for the management of olfactory dysfunction-secondary publication. Auris Nasus Larynx 46:653-662

10. Kattar N, Do TM, Unis GD et al (2021) Olfactory training for postviral olfactory dysfuncion: systematic review and meta-analysis. Otolaryngol Head Neck Surg 164:244-254

11. Choi BY, Jeong H, Noh $\mathrm{H}$ et al (2021) Effects of olfactory training in patients with postinfectious olfactory dysfunction. Clin Exp Otorhinolaryngol 14:88-92

12. Harless L, Liang J (2016) Pharmacologic treatment for postviral olfactory dysfunction: a systematic review. Int Forum Allergy Rhinol 6:760-767

13. Hummel T, Rissom K, Reden J et al (2009) Effects of olfactory training in patients with olfactory loss. Laryngoscope 119:496-499

14. Kollndorfer K, Fischmeister F, Kowalczyk K et al (2015) Olfactory training induces changes in regional functional connectivity in patients with long-term smell loss. Neuroimage Clin 9:401-410

15. Jiramongkolchai P, Jones MS, Peterson A et al (2021) Association of olfactory training with neural connectivity in adults with postviral olfactory dysfunction. JAMA Otolaryngol Head Neck Surg. https://doi.org/10.1001/jamaoto.2021.0086

16. Soler ZM, Patel ZM, Turner JH et al (2020) A primer on viralassociated olfactory loss in the era of COVID-19. Int Forum Allergy Rhinol 10:814-820

17. Imam SA, Lao WP, Reddy $P$ et al (2020) Is SARS-CoV-2 (COVID-19) postviral olfactory dysfunction (PVOD) different from other PVOD? World J Otorhinolaryngol Head Neck Surg 6(Suppl 1):S26-S32

18. Le Bon S-D, Konopnicki D, Pisarski N et al (2021) Efficacy and safety of oral corticosteroids and olfactory training in the management of COVID-19-related loss of smell. Eur Arch Otorhinolaryngol. https://doi.org/10.1007/s00405-020-06520-8

19. Hopkins C, Alanin M, Philpott C et al (2021) Management of new onset loss of sense of smell during the COVID-19 pandemicBRS consensus guidelines. ClinOtolaryngol 46:16-22

Publisher's Note Springer Nature remains neutral with regard to jurisdictional claims in published maps and institutional affiliations. 